\title{
ANALISIS KEMAMPUAN TEKNOLOGI PT X DENGAN PENDEKATAN TEKNOMETRIK DAN ANALYTICAL NETWORK PROCESS (ANP)
}

\author{
Bambang Adiantoro \\ Program Studi Magister Operasi Laut, Sekolah Staf dan Komando TNI Angkatan Laut \\ Jakarta Selatan \\ email: adiantoro01@gmail.com
}

\begin{abstract}
Analysis of technology capability of PT X using Teknometrik and Analitycal Network Process (ANP) method with the result is Technology Coeficient Contribution (TCC) value and priority development of technology component, for TCC get value of 0.5281 which is in the value range $0.5<T C C \leq 0.7$ its means that the level of technology of $P T X$ in the construction of the ships has a good category and has a semi modern technological level, As for the priorities of the development of technological components showed that Technoware is the first priority with the weighted value of 0.3031 , the second priority component is Orgaware with a weighted value. 0.2968, then the third priority is the Humanware component with a weighted value of 0.2007 and the fourth priority is the Infoware component with a weighted value of 0.1994. The Consistency Ratio (CR) value of 0.00720 indicates that the determination of alternative priorities has been consistent because it has a value of $C R \leq 0.1$. Technoware technology components is very important to develop because it is very influential in supporting the company to focus on consumers with the support of a solid organization as well as professional personnel, can compete in the national ship industry.
\end{abstract}

Keywords: Technological capabilities, Shipbuilding industry, Teknometric, Technoware, Humanware, Infoware, Orgaware, Analitycal Network Process (ANP).

\section{PENDAHULUAN}

Tugas pokok TNI adalah menegakkan kedaulatan negara dan mempertahankan keutuhan wilayah NKRI dilaksanakan melalui operasi militer perang (OMP) salah satunya adalah Operasi Amfibi. dalam Operasi Amfibi peran Kapal Angkut Tank (AT) adalah mutlak yang digunakan untuk mendaratkan pasukan beserta kelengkapannya, namun kapal-kapal tersebut sudah berumur lebih dari 30 tahun, sehingga perlu adanya penggantian baru dan saat ini pembangunan kapal jenis ini sudah dapat dilaksanakan di dalam negeri, yaitu kapal AT 1 sampai dengan AT 7.

PT $X$ telah selesai membangun kapal AT 3 dan 4 serta dalam proses pembangunan kapal AT 5,6 dan 7, pembangunan mulai dilaksanakan pada tahun 2017 dan sesuai kontrak awal, seharusnya diresmikan pada akhir tahun 2018, namun terjadi keterlambatan pembangunan, hingga April 2019 belum dapat terselesaikan, sehingga perlu dilaksanakan penelitian mengenai Kemampuan Teknologi PT X dalam pembangunan Kapal AT
5,6 dan 7 dengan tujuan untuk mengukur kemampuan teknologi menggunakan metode teknometrik, yang hasilnya berupa nilai Technology Contribution Coefficient (TCC) atau koefisien kontribusi teknologi serta untuk menentukan prioritas pengembangan komponen teknologi PT X.

\section{METODOLOGI PENELITIAN}

Metode penelitian yang digunakan pada penulisan ini adalah metode kuantitatif yang digunakan untuk meneliti komponen teknologi yang dimiliki PT X dalam pembangunan kapal AT, beberapa proses dalam pembangunan kapal, yaitu material handling, accuracy control, steel fabrication, block assembly dan erection, outfitting, blasting dan coating, serta proses pengujian.

Menurut United Nations Economic and Social Commision for Asia and the Pacific UNESCAP (1989) dalam Technology Atlas Project, teknologi dapat dipandang dalam konteks produksi sebagai kombinasi atas empat komponen dasar yang berintegrasi secara dinamis dalam suatu proses transformasi, yaitu sebagai berikut: 
a. Technoware, merupakan Object-Embodied Technology, fasilitas fisik yang gunakan untuk proses operasional yang mencakup peralatan (Tools), perlengkapan (Equipment), mesin-mesin (Machine), alat pengangkutan (Vehicles) dan infrastruktur fisik (Physycal Infrastructure).

b. Humanware, merupakan Person-Embodied Technology, pengguna technoware yang meliputi pengetahuan (Knowledge), keterampilan (Skills), kebijakan (Wisdom), kreativitas (Creativity), pengalaman (Experience).

c. Inforware, merupakan Document-Embodied Technology, dokumen tertulis maupun elektronik seperti proses (Proceses), prosedur (Procedures), teknik (Techniques) metode (Methods), teori (Theory), spesfikasi (Specifications), pengamatan (Observation) dan keterkaitan (Relationship) yang memungkinkan humanware untuk mendapat informasi dan belajar secara lebih cepat.

d. Orgaware, merupakan Institution-Embodied Technology, teknologi yang melekat pada organisasi yang mencakup praktek-praktek manajemen (Managements Practises), pengaturan organisasional (Organizational Arrangements) yang diperlukan dalam proses transformasi. ini merupakan langkah-langkah yang dilakukan dalam melaksanakan sebuah penelitian.

\section{Prosedur Pengambilan data}

Lokasi penelitian dilaksanakan di salah satu BUMS yang bergerak di industri galangan kapal yaitu PT $\mathrm{X}$ yang terletak di Pelabuhan Tanjung Priok Jakarta Utara, memiliki cabang 2 (dua) unit galangan. Galangan kedua ada di Lamongan, Jawa Timur, dan galangan ketiga berada di Bandar Lampung yang merupakan unit galangan dalam pembangunan kapal Angkut Tank (AT) 5,6 dan 7 pesanan TNI AL, galangan tersebut beralamatkan di Jl. Alamsyah Ratu Prawira Negara, Km 12 Srengsem, Panjang, Bandar Lampung, waktu penelitian dilaksanakan selama penulis melaksanakan pendidikan program magister operasi laut di Seskoal pada tahun 2019.

Pengumpulan data dilaksanakan 2 (dua) tahap, pertama dilaksanakan dengan metode deskriptif komparatif yaitu membandingkan data hasil penelitian terdahulu dengan data yang diambil dari obyek penelitian. Sebagai obyek penelitian yaitu komponen teknologi yang ada di industri galangan kapal PT X. Pengumpulan data tahap dua dengan menggunakan instrumen penelitian berupa kuisioner yang diajukan kepada responden yang memiliki pengalaman atau terlibat langsung dalam pembangunan kapal AT, yaitu Tim satgas proyek pembangunan kapal angkut tank 5,6 dan 7, perwira staf Dinas Pengadaan Angkatan Laut (Disadal) dan Dinas Material Angkatan Laut (Dismatal) serta staf dari PT X.

\section{ANALISIS DAN PEMBAHASAN DATA}

Analisis data menggunakan metode Teknometrik dan Analitycal Network Process (ANP) dengan tahapan sebagai berikut:

1. Menentukan tingkat sofistikasi

2. Perhitungan Tingkat State Of The Art (SOTA)

a. Perhitungan SOTA Technoware

$$
\begin{aligned}
& S T_{i}=\frac{1}{10}\left[\frac{\sum_{k} t_{i k}}{k_{*}}\right] \quad \mathrm{k}=1,2, \ldots \ldots \ldots . . . k_{t} \\
& k_{t}=\text { Jumlah } \text { kriteria komponen technoware } \\
& t_{i k}=\text { nilai kriteria ke-k dari technoware kategori } i
\end{aligned}
$$

b. Perhitungan SOTA Humanware

$$
\begin{aligned}
& S H_{j}=\frac{1}{10}\left[\frac{\Sigma_{I} h_{i j}}{j_{h}}\right] \quad \mathrm{j}=1,2, \ldots \ldots \ldots . . . j_{t} \\
& l_{h}=\text { Jumlah kriteria komponen humanware } \\
& h_{i j}=\text { nilai kriteria ke-i dari humanware kategori } j
\end{aligned}
$$

c. Perhitungan SOTA Infoware

$$
\begin{aligned}
& S I=\frac{1}{10}\left[\frac{\Sigma_{m} f_{m}}{m_{f}}\right] \quad \mathrm{m}=1,2, \ldots \ldots \ldots m_{f} \\
& m_{f}=\text { Jumlah } k \text { kriteria komponen infoware } \\
& f_{m}=\text { nilai kriteria ke-m dari infoware pada } \\
& \text { tingkat perusahaan }
\end{aligned}
$$

d. Perhitungan SOTA Orgaware

$$
\begin{aligned}
& \text { SO }=\frac{1}{10}\left[\frac{\sum_{n} \circ_{n}}{n_{n}}\right] \quad \mathrm{n}=1,2, \ldots \ldots \ldots . . . . . \\
& k_{\circ} \\
& n_{0}=\text { Jumlah kriteria komponen Orgaware } \\
& o_{n}=\text { nilai kriteria ke- } n \text { dari orgaware pada } \\
& \text { tingkat perusahaan. }
\end{aligned}
$$

3. Perhitungan Kontribusi Komponen Teknologi melalui persamaan berikut:

a. Kontribusi komponen Tecnoware (T)

$$
T=\frac{1}{9}[L T+S T(U T-L T)]
$$

b. Kontribusi komponen Humanware $(\mathrm{H})$

$$
H=\frac{1}{9}[L H+S H(U H-L H)]
$$

c. Kontribusi komponen Infoware (I)

$$
I=\frac{1}{9}[L I+S I(U I-L I)]
$$

d. Kontribusi komponen Orgaware (O)

$$
O=\frac{1}{9}[L O+S O(U O-L O)]
$$

Keterangan:

$\mathrm{LT}=$ batas bawah technoware

$\mathrm{UT}=$ batas atas technoware

$\mathrm{ST}=$ SOTA technoware

$\mathrm{LH}=$ batas bawah humanware

$\mathrm{UH}=$ batas atas humanware

$\mathrm{SH}=$ SOTA humanware

$\mathrm{LI}=$ batas bawah infoware

$\mathrm{UI}=$ batas atas infoware

SI = SOTA infoware

$\mathrm{LO}=$ batas bawah orgaware

$\mathrm{UO}=$ batas atas infoware

$\mathrm{SO}=$ SOTA infoware 
4. Perhitungan Intensitas Kontribusi Komponen Teknologi

Perhitungan menggunakan metode Analytic Network Process (ANP) dengan tools super decisions.

5. Perhitungan nilai technology contribution coefficient (TCC)

Menggunakan persamaan sebagai berikut:

$$
T C C=T^{\beta \mathrm{t}} \times H^{\beta \mathrm{h}} \times I^{\beta \mathrm{i}} \times O^{\beta \mathrm{o}}
$$

Dimana :

$\mathrm{T}=$ Nilai kontribusi technoware

$\mathrm{H}=$ Nilai kontribusi humanware

I = Nilai kontribusi infoware

$\mathrm{O}=$ Nilai kontribusi orgaware

$\beta \mathrm{t}=$ Nilai intensitas kontribusi technoware

$\beta \mathrm{h}=$ Nilai intensitas kontribusi humanware

$\beta \mathrm{i}=$ Nilai intensitas kontribusi infoware

ßo $=$ Nilai intensitas kontribusi orgaware

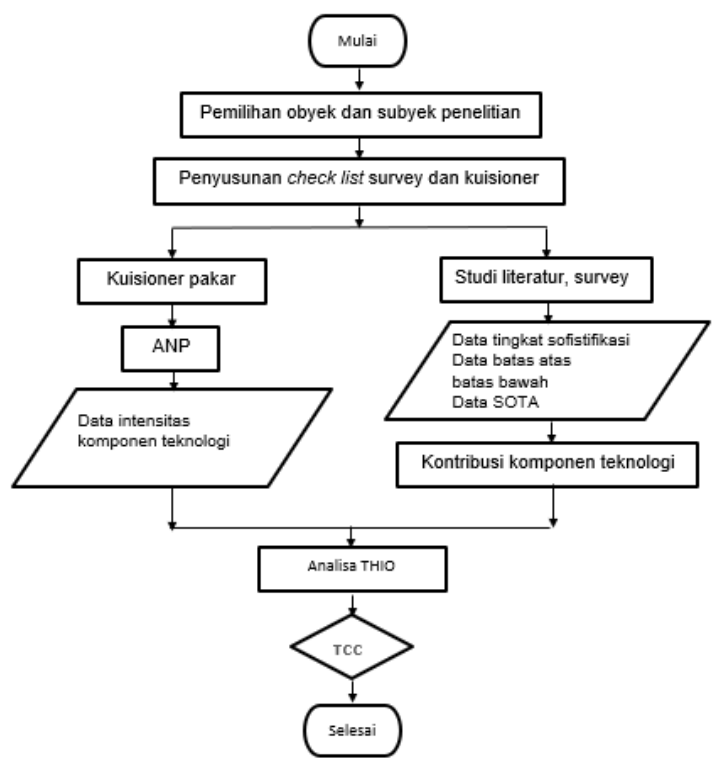

Gambar 1 Diagram kerangka penelitian

Hasil perhitungan didapatkan nilai TCC yang selanjutnya dapat dikategorikan menjadi tingkatan teknologi suatu perusahaan berdasarkan nilai selang TCC dan tingkat teknologi sesuai dengan penelitian terdahulu seperti yang terdapat pada tabel 1 dan tabel 2

Tabel 1 Rentang penilaian TCC Sumber: (Wiraatmaja \& Ma'ruf, 2004)

\section{Tabel 2 Rentang tingkatan teknologi}

\begin{tabular}{ll}
\multicolumn{1}{c}{ Nilai TCC } & Klasifikasi \\
\hline $0,0<$ TCC $\leq 0,3$ & tradisional \\
\hline $0,3<$ TCC $\leq 0,7$ & semi modern \\
\hline $0,7<$ TCC $\leq 1,0$ & modern \\
\hline Sumber: (Wiraatmaja \& Ma'ruf, 2004)
\end{tabular}

Dalam penelitian ini, obyek yang diteliti adalah komponen teknologi dalam pembangunan kapal, sehingga data didapat dari observasi langsung di galangan dengan didahului melaksanakan studi literatur terhadap penelitian terdahulu yang kemudian diperkuat dengan wawancara, dalam penetapan instrumen penelitian diawali dengan diskusi atau Small Group Discussion (SGD) dengan beberapa pihak galangan diluar obyek dan subyek penelitian yang memiliki pengalaman dalam pembangunan kapal.

Untuk subyek penelitian adalah staf PT X sebagai pelaksana atau operator dalam pembangunan kapal angkut tank, kemudian tim satgas sebagai perwira pengawas dalam proses pembangunan, serta perwira staf dari Disadal dan Dismatal sebagai pengendali dan regulator dalam pembangunan kapal angkut tank.

Sebelum pengolahan data dilaksanakan, data hasil penelitian dilaksankan uji validasi dengan mengajukan surat keterangan validasi data kepada direktur PT X untuk dilakasanakan verifikasi terhadap data hasil penelitian dan dinyatakan bahwa data tersebut dinyatakan valid sesuai dengan kondisi yang ada dan dapat digunakan untuk data penelitian tesis.

Teknik pengolahan data yang digunakan adalah metode Teknometrik untuk mengukur kontribusi dari keempat komponen teknologi, yang dinyatakan dalam nilai koefisien kontribusi teknologi atau Technology Contribution Coefficient (TCC), Metode Teknometrik memiliki lima tahapan.

1. Estimasi Tingkat Sofistikasi

Untuk menentukan tingkat sofistikasi pada semua komponen teknologi yang ada di PT X, telah dilaksanakan pengamatan langsung dan telaahan dokumen yang ada serta diperkuat dengan wawancara terhadap pihak-pihak yang terkait dalam pembangunan kapal AT, penentuan nilai tingkat sofistifikasi menggunakan kriteria seperti terdapat pada lampiran B sehingga didapatkan penilaian batas bawah atau Lower Limit (LL) dan batas atas atau Upper Limit (UL), contohnya tingkat sofistikasi dalam proses Steel Fabrication.

PT X membuat rancangan awal (Preliminary Design) yang merupakan pengulangan dari rancangan awal kapal AT sebelumnya yang telah dimodifikasi dan disempurnakan oleh Divisi

\begin{tabular}{|c|c|}
\hline Nilai TCC & Klasifikasi \\
\hline $0,0<\mathrm{TCC} \leq 0,1$ & sangat rendah \\
\hline $0,1<\mathrm{TCC} \leq 0,3$ & rendah \\
\hline $0,3<\mathrm{TCC} \leq 0,5$ & cukup \\
\hline $0,5<\mathrm{TCC} \leq 0,7$ & baik \\
\hline $0,7<\mathrm{TCC} \leq 0,9$ & sangat baik \\
\hline $0,9<\mathrm{TCC} \leq 1,0$ & kecanggihan mutakhir \\
\hline \multicolumn{2}{|c|}{$\begin{array}{l}\text { Rancang Bangun (Engineering) yaitu pembuatan } \\
\text { Key Plan, Detail Plan, dan Production Drawing } \\
\text { Plan. Key Plan adalah gambar-gambar utama }\end{array}$} \\
\hline
\end{tabular}


kapal, salah satunya adalah gambar rencana umum (General Arrangement Plan).

Dalam tahapan desain, PT X menerapankan teknologi sistem produksi yang sudah berbasis komputer yaitu CAD/CAM (computer aided design/computer aided manufacturing), yang dilengkapi dengan perangkat lunak Tribon AVEVA. CAD adalah penggunaan sistem komputer untuk melakukan fungsi-fungsi perancangan kapal atau desain. Sedangkan CAM adalah penggunaan sistem komputer untuk merencanakan, mengatur, dan mengendalikan operasi mesin-mesin produksi berbasis CNC (computer numerical control), sehingga dihasilkan mutu produksi yang lebih baik karena proses fabrikasi yaitu pemotongan material pelat dilakukan dengan mesin-mesin otomatis, hal ini membantu dalam proses Accuracy Control dengan tujuan untuk menghindari terjadinya penyimpangan dimensi dan geometri pada saat penyambungan blok badan kapal atau Erection.

Seluruh material yang telah difabrikasi digabungkan dan dirakit menjadi satu dimensi yang lebih besar dan kompak yang disebut block. Dalam proses ini, peralatan yang diperlukan adalah Cran dan Forklift yang digunakan untuk mengangkat, memindahkan dan merubah posisi dari panel-panel dan blok (Material Handling) untuk dilaksanakan proses Erection. peralatan ini masih bersifat umum yang juga digunakan pada tahap lainnya.

Dari keterangan diatas maka dapat diambil data mengenai tingkat sofistikasi komponen technoware dimana nilai batas bawah atau Lower Limit (LL) adalah 4 (empat) didapat dari proses Material Handling dimana komponen teknologi yang digunakan masih bersifat umum. Untuk batas atas atau Upper Limit (UL) mendapat nilai 6 (enam) didapat pada proses Accuracy control dan Steel Fabrication yang menggunakan komponen teknologi berbasis komputer.

Demikian pula untuk mendapatkan nilai tingkat sofistikasi komponen teknologi Humanware, Infoware dan Orgaware dilaksankan dengan cara yang sama sehingga akan didapat data tingkat sofistikasi semua komponen teknologi. Daftar nilai tingkat sofistikasi teknologi yang dimiliki PT X dalam pembangunan kapal AT dapat dilihat pada tabel 3 berikut:

Tabel 3 Daftar nilai tingkat sofistifikasi komponen teknologi

\begin{tabular}{c|c|c|l}
\hline \multirow{2}{*}{$\begin{array}{c}\text { Komponen } \\
\text { Teknologi }\end{array}$} & \multicolumn{2}{|c|}{$\begin{array}{l}\text { Tingkat } \\
\text { Sofistikasi }\end{array}$} & \multicolumn{1}{c}{ Keterangan Teknis } \\
\cline { 2 - 4 } Technoware & LL & UL & \\
\hline Humanware & 4 & 6 & $\begin{array}{l}\text { LL: Peralatan yang digunakan pada proses material handling masih bersifat } \\
\text { mekanik. } \\
\text { UL: pada proses accuracy control dan steel fabrication sudah menggunakan } \\
\text { peralatan yang berbasis komputer. }\end{array}$ \\
\hline Infoware & 4 & 5 & $\begin{array}{l}\text { LL: Personil PT X mampu melaksanakan perawatan fasilitas peralatan } \\
\text { Technoware pada proses material handling, assembly dan erection, outfitting, } \\
\text { blasting, coating serta testing. } \\
\text { UL: kemampuan personil PT X dalam mengelola fasilitas peralatan technoware } \\
\text { pada proses accuracy control dan fabrikasi }\end{array}$ \\
\hline Orgaware & 4 & 6 & $\begin{array}{l}\text { LL: memiliki kemampuan mengolah informasi terkait peralatan proses operasi } \\
\text { (SOP, panduan). } \\
\text { UL: mampu menyediakan dan mengolah informasi untuk efektifitas dan efisiensi } \\
\text { terkait informasi aplikasi yang digunakan (CAD/CAM). }\end{array}$ \\
\hline
\end{tabular}

Sumber: Diolah penulis (2019)

\section{Perhitungan Tingkat State Of The Art (SOTA)}

Dalam penentuan nilai state of the art komponen teknologi PT X mengacu pada Framework technology development UNESCAP dengan kriteria yang didapat berdasarkan dari studi literatur dan hasil SGD dengan para pakar yang membidangi teknologi pembangunan kapal, penentuan nilainya dengan menggunakan metode skoring 1 s.d. 10, terhadap semua komponen teknologi PT X. 
a. Perhitungan SOTA Technoware

$$
\begin{aligned}
S T_{i} & =\frac{1}{10}\left[\frac{\sum_{k} t_{i k}}{k_{*}}\right] \\
& =\frac{1}{10}\left[\frac{4+6+6+4+4+5+5}{\mathbb{T}}\right] \\
& =0,486
\end{aligned}
$$

b. Perhitungan SOTA Humanware

$$
\begin{aligned}
S_{j} & =\frac{1}{10}\left[\frac{\sum_{i} h_{i j}}{j h}\right] \\
& =\frac{1}{10}\left[\frac{4+5+5+4+4+4+4}{7}\right] \\
& =0,429
\end{aligned}
$$

c. Perhitungan SOTA Infoware

$$
\begin{aligned}
S I & =\frac{1}{10}\left[\frac{\sum_{m} f_{m}}{m_{f}}\right] \\
& =\frac{1}{10}\left[\frac{4+4+5+4+4+4+5}{7}\right] \\
& =0,429
\end{aligned}
$$

d. Perhitungan SOTA Orgaware

$$
\begin{aligned}
\text { SO } & =\frac{1}{10}\left[\frac{\sum_{n} 0_{n}}{n_{n}}\right] \\
& =\frac{1}{10}\left[\frac{4+6}{6}\right] \\
& =0,500
\end{aligned}
$$

3. Perhitungan Kontribusi Komponen Teknologi

Perhitungan nilai kontribusi masing-masing komponen teknologi dilakukan dengan menggunakan nilai batas atas dan batas bawah derajat kecanggihan serta hasil perhitungan rating state of the art (SOTA) yang diformulasikan melalui persamaan berikut :

a. Nilai kontribusi komponen Technoware

$$
\begin{aligned}
T & =\frac{1}{9}[L T+S T(U T-L T)] \\
& =\frac{1}{9}[4+0,486(6-4)] \\
& =0,552
\end{aligned}
$$

b. Nilai kontribusi komponen Humanware

$$
\begin{aligned}
H & =\frac{1}{9}[L H+S H(U H-L H)] \\
& =\frac{1}{9}[4+0,429(5-4)]
\end{aligned}
$$

$$
=0,492
$$

c. Nilai kontribusi komponen Infoware

$$
\begin{aligned}
I & =\frac{1}{9}[L I+S I(U I-L I)] \\
& =\frac{1}{9}[4+0,429(5-4)] \\
& =0,492
\end{aligned}
$$

d. Nilai kontribusi komponen Orgaware

$$
\begin{aligned}
O & =\frac{1}{9}[L O+S O(U O-L O)] \\
& =\frac{1}{9}[4+0,500(6-4)] \\
& =0,555
\end{aligned}
$$

4. Perhitungan Intensitas Kontribusi Komponen Teknologi

Perhitungan nilai intensitas kontribusi komponen teknologi didapat dengan menggunakan metode ANP (Analytic Network Process). Instrument yang digunakan untuk mendapatkan informasi tingkat kepentingan komponen teknologi melalui kuisioner terhadap responden pakar.

Tabel 4. Hasil pembobotan alternatif menggunakan super decisions

\begin{tabular}{|c||c||c|c||c|c||}
\hline Graphic & Alternatives & Total & Normal & Ideal & Ranking \\
\hline \hline 0 & HUMANWARE & 0.1051 & 0.2007 & 0.6619 & 3 \\
\hline \hline & INFOWARE & 0.1045 & 0.1994 & 0.6579 & 4 \\
\hline \hline & ORGAWARE & 0.1555 & 0.2968 & 0.9791 & 2 \\
\hline \hline & TECHNOWARE & 0.1588 & 0.3031 & 1.0000 & 1 \\
\hline \hline
\end{tabular}

Sumber: diolah dengan super decision, 25 Juni 2019

Dengan hasil komponen teknologi yang memiliki prioritas pertama untuk dilaksanakan pengembangan adalah komponen Technoware dengan nilai pembobotan 0, 3031, untuk urutan kedua adalah komponen Orgaware dengan nilai pembobotan 0,2968, urutan ketiga adalah komponen Humanware dengan nilai pembobotan 0,2007 dan urutan yang terakhir adalah komponen Infoware dengan nilai pembobotan 0,1994, keempat hasil nilai tersebut merupakan nilai intensitas kontribusi komponen teknologi.

5. Perhitungan Nilai TCC

Setelah didapat nilai kontribusi dan nilai intensitas kontribusi dari masing-masing komponen teknologi maka tahap berikutnya untuk mendapatkan nilai TCC (technology contribution coefficient) adalah dengan memasukkan nilai tersebut kedalam suatu formulasi sebagai berikut:

$T C C=T^{\beta \mathrm{t}} \times H^{\beta \mathrm{h}} \times I^{\beta \mathrm{i}} \times O^{\beta \mathrm{o}}$ 
Tabel 4 Nilai Koefisien Kontribusi Komponen Teknologi

\begin{tabular}{|c|c|c|c|c|}
\hline Komponen Teknologi & Nilai SOTA & Nilai Kontribusi & $\begin{array}{c}\text { Nilai Intensitas } \\
\text { Kontribusi }\end{array}$ & TCC \\
\hline Technoware & 0,468 & 0,552 & 0,3031 & \multirow{4}{*}{0,5281} \\
\hline Humanware & 0,429 & 0,492 & 0,2007 & \\
\hline Infoware & 0,429 & 0,492 & 0,1994 & \\
\hline Orgaware & 0,500 & 0,555 & 0,2968 & \\
\hline
\end{tabular}

Dari tabel diatas menunjukkan hasil dari perhitungan dengan menggunakan pendekatan metode teknometrik terhadap kemampuan teknologi yang dimiliki oleh PT X, yaitu nilai SOTA, nilai kontribusi dan nilai intensitas kontribusi serta nilai akhir, yaitu koefisien kontribusi teknologi (TCC) sebesar 0,5281 .

\section{KESIMPULAN}

Dengan melihat hasil dari perhitungan nilai TCC yaitu sebesar 0,5281 dan merujuk keterangan yang ada pada tabel 1 yaitu mengenai rentang penilaian TCC dan tabel 2 mengenai rentang tingkatan teknologi, menyatakan bahwa kemampuan teknologi PT X berada pada rentang nilai $0,5<\mathrm{TCC} \leq 0,7$ dapat dikatakan bahwa, tingkat kemampuan teknologi PT X dalam melaksanakan pembangunan kapal angkut tank dikategorikan memiliki kemampuan yang "baik" dan memiliki tingkatan teknologi "semi modern". Hal ini diperkuat dengan bukti bahwa PT X merupakan Industri galangan nasional pertama yang berhasil membangun kapal jenis Angkut Tank 3 dan 4, namun nilai 0,5281 tersebut merupakan nilai terendah dari rentang nilai dengan klasifikasi baik, sehingga PT X perlu untuk meningkatkan nilai TCC menjadi lebih tinggi lagi agar dapat bersaing dengan industri galangan kapal yang lainnya.

Nilai koefisien kontribusi teknologi (TCC) yang dimiliki oleh PT X sangat dipengaruhi oleh nilai kontribusi teknologi pada masing-masing komponen teknologi yang dimiliki terutama yang memiliki nilai intensitas kontribusi yang tinggi yaitu komponen teknologi technoware dan komponen teknologi orgaware sehingga PT X perlu melaksanakan pengkajian ulang terhadap batas bawah tingkat sofistikasi yang dimiliki komponen-komponen teknologi tersebut. Selain dari pada itu peningkatan terhadap batas atas tingkat sofistikasi serta nilai State Of The Art (SOTA) pada komponen-komponen teknologi tersebut juga perlu dilaksanakan agar dapat meningkatkan nilai kontribusi pada masingmasing komponen teknologi tersebut. Nilai kontribusi yang meningkat akan memberikan dampak meningkatnya pula nilai koefisien kontribusi teknologi (TCC) PT X.

Perencanaan dan pengembangan komponen teknologi Technoware sangat penting untuk dikembangkan karena sangat berpengaruh dalam mendukung perusahaan untuk fokus terhadap konsumen dengan didukung oleh organisasi yang solid serta personil yang profesional agar dapat bersaing diindustri galangan kapal nasional.

\section{DAFTAR PUSTAKA}

Achmad Fauzan, Yopi Novita dan Vita Rumanti K. (2009). Penilaian Tingkat Teknologi Dok Pembinaan Unit Pelaksana Teknis Balai Teknologi Penangkapan Ikan (UPT BTPI) Muara Angke.

Evi Rusmanida Yanthi. (2018). Analisis Kontribusi Komponen Teknologi (Technoware, Humanware, Infoware, Orgaware) Pada Perusahaan Jasa Transportasi Kereta Api Barang Dengan Pendekatan Model Teknometrik.

Fitria Fresty Lungari, (2017). Analisis Kesiapan Komponen Teknologi (Humanware) di Galangan Kapal Menengah.

John W. Crteswell. (2009). Research Design, Pendekatan kualitatif, kuantitatif dan mixed. (Ahmad Fawaid, Penerjemah). Yogyakarta. Pustaka Pelajar.

Nazaruddin. (2008). Manajemen Teknologi. Yogyakarta. Graha ilmu.

Noor Virliantarto, Buana Ma'ruf, Ketut Suastika. (2017). Pengukuran Kesiapan Teknologi untuk Membangun Kapal Kontainer 100 Teus Dengan Sistem Modular di PT PAL Indonesia.

Rusydiana, A. S., \& Devi, A. (2013). Analytic Network Process: Pengantar Teori dan Aplikasi. Bogor: Smart Publishing.

Shipbuilding Technologi and education, Washington, D.C. National Academy Press, 1996.

Vanany, I. (2004). Aplikasi Analytic Network Process (ANP) pada perancangan sistem pengukuran kinerja (studi kasus pada PT $X)$. Jurnal Teknik Industri, 5(1). 